\title{
REALTIME NATIONAL HEALTH INSURANCE SCHEME (RNHIS): MEANS TO ACHIEVE HEALTH FOR ALL
}

\author{
${ }^{1}$ Alimi O. Maruf, ${ }^{2}$ Binuyo O. G., ${ }^{3}$ Gambo I. G. and ${ }^{4}$ K. Jimoh \\ ${ }^{1}$ Computer Science Unit, Department of Physical Sciences Al-Hikmah University, Ilorin, \\ Nigeria \\ ${ }^{2}$ African Institute for Science Policy and Innovation Obafemi Awolowo University, Ile \\ Ife, Nigeria \\ ${ }^{3}$ Computer Science and Engineering Department Obafemi Awolowo University, Ile Ife, \\ Nigeria \\ ${ }^{4}$ Statistics Unit, Department of Physical Sciences Al-Hikmah University, Ilorin, Nigeria
}

\begin{abstract}
E-health, tele-medicine, and informatics are terms prominent in the health sector nowadays; Real-time Health Insurance should be among. The laudable program, National Health Insurance Scheme (NHIS) introduced in Nigeria can only be effective and efficient with the introduction of dynamic and integrated online NHIS system. Data were gathered through document examination, internet and interview of NHIS desk officers, health record officers, and NHIS accountant in two of our tertiary hospitals. Data were analysed and graphs were drawn to show current status. Software Engineering architecture for its development for better system was introduced. From the data analysed, it was found that none of the current Nigeria HMOs, Health Facilities (HFs) and NHIS headquarters is fully computerised and networked which is making the current system epileptic. People on transit and rural areas are not adequately catered for. Therefore, a workable Real-time Health Insurance Scheme will help people on transit and bridge urban-rural health divide.
\end{abstract}

\section{Keywords}

Integration, Software-engineering, Health, Insurance, Urban-rural, Real-time

\section{INTRODUCTION}

Health for all by the year 2020 as proposed by the government can only be achieved through well planned health policy and the use of information technology. In US, The National Health Interview Survey (NHIS) has monitored the health of the nation since 1957[1]. NHIS Act 35 of 1999 was introduced and implemented in Nigeria, around $29^{\text {th }}$ May, 2005 to be specific [2]. In order to reduce 
fraudulent practices and make health facility available anywhere, online NHIS health programme will help rural dwellers and people on transit immensely so far the NHIS card is available. But due to unavailability of online system, it is impossible presently to confirm the information related to the people on transit, curb fraudulent practices and the use of fake cards.

HMO as an independent organisation can not synchronize their accounts especially from the health facilities (hospitals and clinics) easily without computerisation. The contribution from Employee (1.75 or 5\%) Employer (3.25 or 10\%) public or private and other stakeholders can be easily monitored with online system [3]. The use of real-time NHIS system will make life easier for every individual and bridge the gap between urban and rural members of NHIS. Many Social Health Insurance Programmes such as TISHIP, VCSHIP, ISSHIP, CBSHIP, and FSSHIP introduced by NHIS headquarters can only be fully successful if dynamic online patient system is added.

\section{CURRENT HEALTH INSURANCE SCHEME}

Many countries of the world have introduced NHIS and their citizens are now enjoying it. But most of them are yet to have real-time system as proposed by this research. Not only that, majority focused on formal sector only while the formal sector is at Federal Government level only. Participation by other government arms (State and LGA), private organization, individuals and people from rural areas can be attributed to affordability. Understanding the affordability of coverage is important for evaluating the role of policy in reducing the number of uninsured workers. Since others and group of people are yet to join, MDG achievement on health is not yet feasible [4].

Why Small Firms are less likely than Big Firms to Offer Health Insurance? Small firms are substantially less likely than large firms to offer health insurance due to higher loading and administrative costs for small firms, differences in the workforces, and adverse selection. The two major factors that account for the discrepancy in offer rates between large and small firms are, first, the composition of the workforce and, second, the dispersion effect [5].

Area Resource File (ARF) is a county-specific health resources information system designed to be used by planners, policymakers, researchers, and other professionals interested in the nation's health care delivery system and factors that may impact health status and health care in the U.S. It is a database that contains information on health facilities, health professions, measures of resource scarcity, health status, economic activity, health training programs, and socioeconomic and environmental characteristics. In addition, Healthcare Cost and Utilization Project (HCUP) data collections are used for research on hospital utilization, access, charges, quality and outcomes at the national, regional, and state levels. The data are also usefully applied to patterns of care for diseases as well as for the study of population sub-groups such as minorities, children, women, and the uninsured. This can be applied in different nations for better NHIS delivery [6].

Towards a national health insurance system in Yemen, a study on situation assessment and proposals for a national health insurance system was conducted. It tries to convert out-of-pocket spending in case of illness into regular small prepayments of many citizens. This allows providing health care according to the need and not only according to the ability to pay, especially in case of catastrophic illnesses. 
Mass poverty, high population growth and insufficient public services in the context of an oil dependent economy like Nigeria, characterizes Yemen [7].

In Africa, Ghana and South Africa are already having NHIS. [8] Who analyzed Ghana health program and the way forward, said "The first wealth is health". "In health there is freedom. Health is the first of all liberties". "It is health that is real wealth and not pieces of gold and silver".

In Nigeria today, you can register online and have account with NHIS. You will be allowed to view dependants' details and manage your account. They promise to that, in future, you will be able to select your healthcare facility for yourself and an alternative healthcare facility for all or some of your dependants if you are not residing in the same location [9].

The NHIS indicators from different nations show importance of NHIS to make healthcare available and affordable for people. Every citizen of a nation such as working class, market men and women, government at federal, state, local government and so on should be given opportunity to benefit from the system.

\section{OBJECTIVES}

This article is to let government at any level, HMOs, Health facilities, individuals and all other stakeholders theoretically know that, introduction of integrated and centralized real-time NHIS system will make health insurers have access to health services when on transit and bridge urban-rural health divide. In addition, stakeholder's network will bring transparency, add control, make accounting and auditing easier for its administrators to achieve health component of millennium development goal pursued by many countries of the world today.

\section{METHODOLOGY}

The officers in charge of the NHIS give the necessary documents while health record officers were interviewed along with their desk officers and NHIS accountants. Other data gathering instruments used includes internet, document examination and direct observation. Software development requirements and software engineering architecture for better integrated system development were inclusive.

\section{SURVEY DATA ANALYSIS AND RESULTS}

Two hospitals were used to assess the level of participation of HMO and patients, one from the Northern part of Nigeria and one from the southern part of Nigeria. Presently, only federal government workers are fully insured while some states may likely join in future. These two health facilities help us to have the view of both parts of the country. The table is as follows. 
Table 1: Selected Health Facilities and Number of HMOs.

\begin{tabular}{|l|l|l|l|l|}
\hline SN & HEALTH FACILITY & $\begin{array}{l}\text { NO OF } \\
\text { HMO }\end{array}$ & $\begin{array}{l}\text { NO OF } \\
\text { PATIENT }\end{array}$ & AVERAGE \\
\hline 1 & $\begin{array}{l}\text { Usmanu Danfodiyo University } \\
\text { Teaching Hospital, Sokoto. }\end{array}$ & 1,681 & 93 \\
\hline 2 & $\begin{array}{l}\text { Obafemi Awolowo University } \\
\text { Teaching Hospital, Ile-Ife. }\end{array}$ & 18 & 1,935 & 108 \\
\hline
\end{tabular}

Out of fifty-nine (59) HMOs on NHIS website, it was found that, eighteen (18) HMOs each are involved in both tertiary hospitals, none is fully computerised and networked, average of 93 patients attended from UDUTH HMOs. Also, average of 108 patients from OAUTH, Ile Ife compared to that of Sokoto shows no much significant difference.

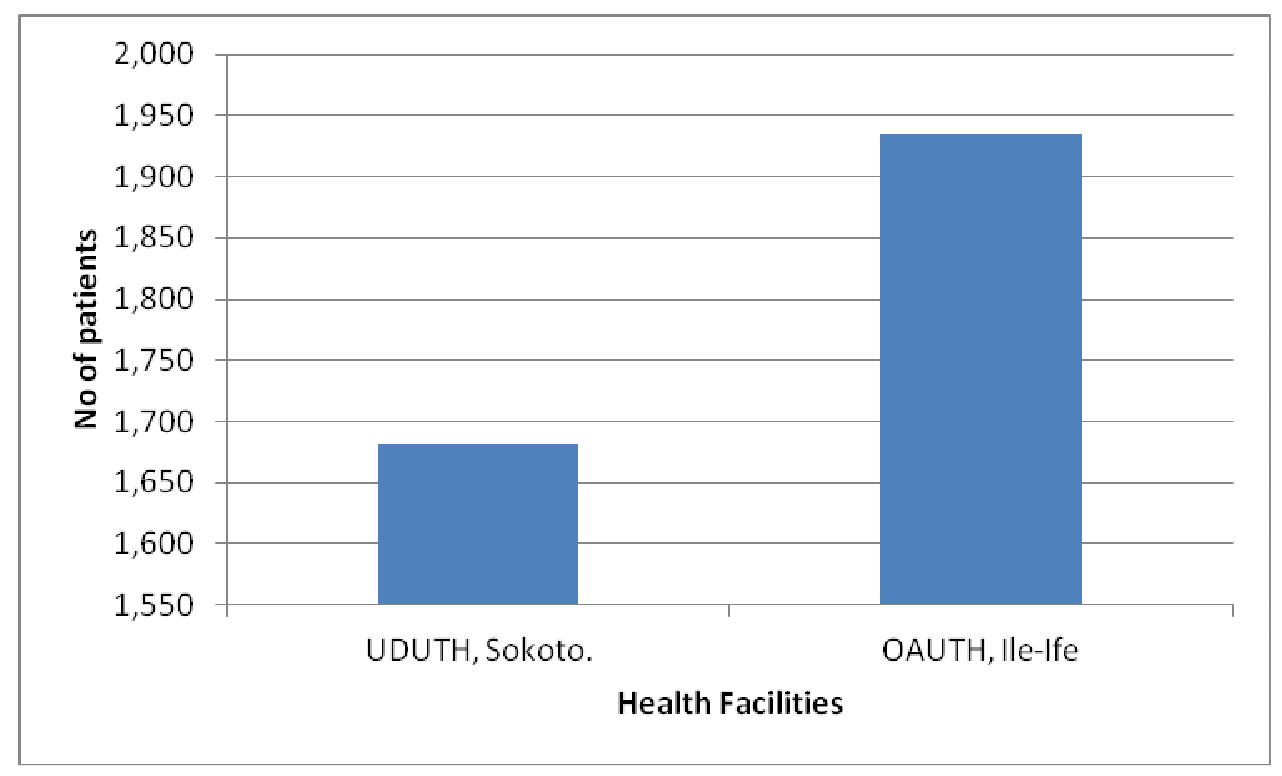

Fig. 1: Bar-chart showing patient population for health facilities

Figure one shows that OAUTH Ile-Ife has more patients than UDUTH, Sokoto which implied there is need for more mobilization in the North compared to the Southern part of the country. 


\subsection{Internet connectivity and bridging of urban-rural divide}

Online system is the order of the day for prompt and faster services to customers these days. Connections of all the systems like ATM in the banking sector could be of better experience if HMOs, Health facilities and other important stakeholders can be connected. Not only connected but should be real-time such that any patient or people on transit can branch to any health facility anywhere with NHIS card and being attended to with all the necessary information accessed online.

Presently, GSM is available in both rural; and urban areas throughout the country. The Health facilities, both urban and rural areas can have internet services to network all stakeholders. The stakeholders must be able to have internet connectivity for 24/7 without any interruption. GSM network providers can serve as ISP. With MODEM or handset; we can have access to the internet in rural areas. All NHIS's clinics, or hospitals in the rural areas will only need generator in case of non availability of electricity from the national grid, or smart-phones connected to any GSM network provider and modems if computers are to be used to access patient information in rural areas. Clouding should also be considered for data security and to guide against unforeseen circumstances. Security of data and cyber space problems should be put into consideration for NHIS pooled Information security.

\section{SOFTWARE AND SYSTEM ARCHITECTURE NEEDED}

Reliable software system is the most important component in any system, ATM, GSM and other systems are only working when the software are working. Real-time NHIS cannot be achieved without workable, reliable, flexible, and standard software. Dysfunctional system product occurred without proper software design, therefore, cleanroom software engineering technique, which is team oriented is proposed to guide against error rework.

In addition, system development needs a better architecture for a successful system development. Software engineering architectures such as client server, distributed and inter-organisational for this system need special analysis and special attention due to resource sharing, openness, concurrency, scalability, and fault tolerance. [10] Stated that technical knowledge areas that are relevant to professional software engineers include requirements, design, construction, testing, maintenance, configuration management process, tools, methods and quality. These must be followed religiously by the developer in order to have reliable system. Fat-client model as mentioned by Sommerville in figure 2 would be necessary.

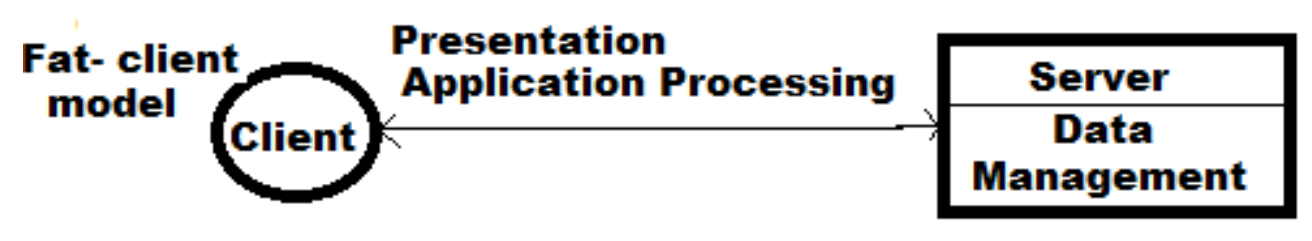

Fig. 2: Fat-Client Model 
This makes use of application logic processing and the presentation to the clients. The server is the transaction server that manages all database transactions.

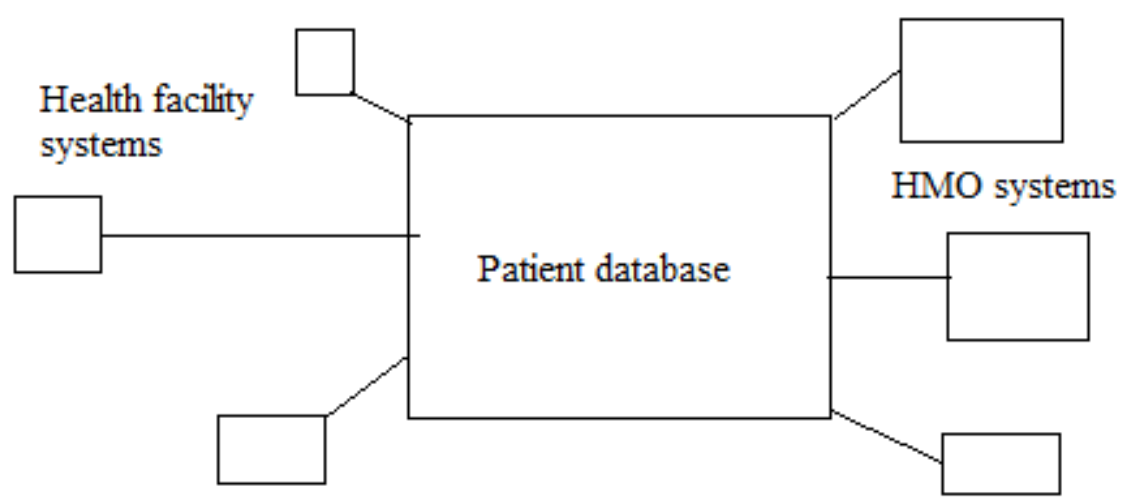

Fig. 3: Central system connected to other stakeholders

Figure 3 shows the NHIS registered patient database that is centrally controlled with NHIS hospitals and HMOs accessing information centrally. This can also be connected to Server-oriented system architecture.

\section{IMPLEMENTATION}

Presently, dot ng NHIS website is partially static and not fully integrated with other stakeholders, while many systems are being centralised in Nigeria and dynamic, among them are, IPPIS for payment of federal government staff salaries, GIFMIS for budget implementation through CBN for ministries and MDAs, and TSA for all government incomes. To implement this new system will not be too difficult, what is necessary is to develop reliable software to manage NHIS centrally. Pilot conversion may be used where only few health facilities starts first and others follow later after it is being satisfied. Parallel conversion can also serve but it may be costly due to extra hands and materials that may be required.

\section{DISCUSSION}

Current system is yet to be fully standardized due to disintegration and coordination problem from the centre and other stations. The new system will make central coordination easy, monetary requirements for payment monitored easily, make management of HMOs have access to the necessary information online, and fund disbursement balances better. Furthermore, synchronization of stakeholders accounts, easy use of any hospital by patients, health for all policy achieved, easy auditing and eradicate the fake claims from different quarters. The real-time system is necessary for prompt reply to any request because of emergencies that requires immediate response and answer to all necessary questions related to a patient. 
International Journal of Computer Science, Engineering and Applications (IJCSEA) Vol.6, No.2, April 2016

\section{RNHIS MERITS TO THE STAKEHOLDERS}

The merits can be categorised as follows:

S Hospitals: Introduction of online verification of patients who are not resident in the area will be easier since they can easily check and see the information related to such patient, they can send messages to the HMO and to the centre including cost of such patient's management.

S Populace: People will have access to health facilities anywhere they may be, since online verification is possible by all HFs which will bridge urban-rural health divide and people on transit.

S Government: Current Sustainable Development goal or Millennium development goal of health for all will be achieved since anybody can be attended to at any time and anywhere no matter your geographical zone.

S NHIS office: Coordination and prompt information related to all HFs, HMO, Accounts, balances, payments, and so on can be monitored if properly integrated and computerized.

S HMOs: The number of patients they have and how disperse they are treated in different HFs will be available online at all times. Daily access to information related to their clients and balances to pay to HFs will be of immense benefit to them.

S Rural Areas: People in the rural areas can also join and their information can be seen online by the stakeholders. This will also bring urban-rural health divide to the barest minimum.

\section{CONCLUSION AND RECOMMENDATIONS}

Conclusively, this is an added advantage to the present system. Therefore, Government should try and add centralize real-time NHIS system to the health insurance policy and give a deadline to the stakeholders. People from rural areas should be sensitized to join to have health for all government policy. State and Local governments should also be compelled to join to be able to achieve the millennium development goals objective on health.

\section{REFERENCES}

[1] Center for Disease Control (US) (2016). National Health Interview Survey. http://www.cdc.gov/nchs/nhis.htm. Page last reviewed: February 19, 2016.

[2] National Health Insurance Scheme (NHIS) (2005): Nigeria NHIS Hand Bill.

[3] NHIS Operational Guidelines (2016). www.nhisonline.com.ng/file/repository.

[4] Didem Bernard, Jessica Banthin, and William Encinosa, (2003). Affordability of Health Insurance: Pennsylvania State University.

[5] Chapin White, M.P.P., David Auerbach, and Stuart Hagen (2009). Why Small Firms Are Less Likely than Big Firms to Offer Health Insurance? Health and Human Resources division, Congressional 
International Journal of Computer Science, Engineering and Applications (IJCSEA) Vol.6, No.2, April 2016

Budget Office, Ford House Office Building, Room 424c, Washington, DC 20515; Tel: 202-226-4931; Fax: 202-225-3149; Email:chapin_white@ post.harvard.edu

[6] Ruth Taylor (2004). Center for the Study of Healthcare Management (CSHM), University of Minnesota.rtaylor@csom.umn.eduor 612-624-1521.

[7] Detlef Schwefel, Jamal Nasher, et al (2005). Towards a national health insurance system in Yemen . Deutsche Gesellschaft für Technische Zusammenarbeit (GTZ)

[8] Nana Yawossei (2008). National Health Insurance Scheme: Health care for all , LONDON , UK

[9] www.nhisonline.com.ng (Accessed 22nd February, 2016)

[10] Sommerville I. (2004). Software Engineering, Seventh Edition, Pearson Addison Weskey, Pearson Education Limited, Edinburg Gate, Harlow, England. 